19. Семенов А.А. Методическая подготовка учителей биологии в контексте ФГОС общего образования и профессионального стандарта педагога // Биологическое и экологическое образование в школе и в вузе: теория, методика, практика: сборник статей междунар. науч.-практ. конф. (21-24 ноября 2016 г.). Вып. 15, Санкт-Петербург / под ред. проф. Н.Д. Андреевой. СПб.: Свое издательство, 2016. С. 174-176.
20. Семенов А.А., Носова Т.М., Колыванова Л.А. Подготовка магистров биологического образования к осуществлению научно-исследовательской деятельности // Інноваційний розвиток вищої освіти: глобальний та національний виміри змін: матеріали III Міжнародної науково-практичної конференції (6-7 квітня 2016 року, м. Суми). Суми: Вид-во СумДПУ імені А.С.Макаренка, 2016. Т. 1. С. 177-181.

\title{
MULTIFUNCTIONAL TRAINING OF FUTURE TEACHERS IN CONTEXT OF FEDERAL STATE EDUCATIONAL STANDARDS AND PROFESSIONAL STANDARD OF PEDAGOGUE
}

(C) 2017

Semenov Alexander Alexeevich, candidate of biological sciences, associate professor, head of Chair of Biology, Ecology and Methods of Teaching

Solovieva Vera Valentinovna, doctor of biological sciences, professor of Chair of Biology, Ecology and Methods of Teaching

Yaitsky Andrey Stepanovich, senior lecturer of Chair of Biology, Ecology and Methods of Teaching Samara State University of Social Sciences and Education (Samara, Russian Federation)

Abstract. Pedagogical activity is multifunctional in nature. Multifunctionality of the teacher's activity is obliged by the requirements of the Federal State Educational Standards of Higher Education as well as the teacher's professional standard. Multifunctional training of future teachers is the process (and result) of mastering by the pedagogic bachelors and masters of set of competencies aimed at fulfilling various teacher functions. There are six basic functions of the modern teacher identified: pedagogical, project, research, methodological, managerial and culturaleducational. The pedagogical function is complex in nature and includes a number of other functions: tutoring, education, developing and correction. All of them are interrelated. The article outlines characteristics of mentioned above functions, describes the track record of training of future teachers at Faculty of Natural Sciences and Geography of Samara State University of Social Sciences and Education as part of baccalaureate and magistracy programs of pedagogical education. This consists of updating of courses content that are implemented according to the student selection, development and realization of new ones, organization and execution of training and production practices, educational and research works of students, scientific conferences, student competitions and olympiads, publication of scientific collected papers (including student ones). Article also presents the results of surveys of graduates on the quality of their preparation for the various teaching functions.

Keywords: pedagogical education; multifunctionality; multifunctional training; future teachers; bachelors; masters; students; pedagogical activity; pedagogue; teacher; functions of teacher; Federal State Educational Standard; Professional Standard of Pedagogue.

УДК 378.6

Статья поступила в редакцию 02.06.2017

\section{МОДЕЛИРОВАНИЕ КУРСА ИНТЕГРИРОВАННЫХ ЗАНЯТИЙ ПО АНГЛИЙСКОМУ ЯЗЫКУ И ЛИТЕРАТУРЕ В ЮРИДИЧЕСКОМ ВЕДОМСТВЕННОМ ВУЗЕ}

(C) 2017

\author{
Скобелева Оксана Олеговна, кандидат педагогических наук, \\ заместитель начальника кафедры философии и общегуманитарных дисциплин \\ Самарский юридический институт ФСИН России (2. Самара, Российская Федеращия)
}

\footnotetext{
Аннотация. В данной статье рассматривается проблема совершенствования языковых и культурологических навыков обучающихся посредством внедрения в образовательный процесс интегрированных занятий по иностранному языку и литературе. Интеграция культур при обучении курсантов ведомственных юридических вузов является важным элементом подготовки специалистов, компетентность которых во многом определяется не только профессиональными навыками, но и умениями пользоваться иностранным языком в рамках установления контактов с представителями других культур, умениями самостоятельно работать с научной и практической документацией и литературой, вести деловую переписку и переговоры. В работе обозначены основания разработки интегрированного курса английского языка и литературы, предложены серии занятий по межпредметным взаимодействиям. Проведенные исследования показали, что межпредметные связи на занятиях иностранного языка положительно сказываются на качестве образовательного процесса: расширяется кругозор курсантов, повышается мотивационная сторона обучения, активизируется учебно-исследовательская деятельность, формируется нравственное воспитание, развиваются коммуникативные навыки обучаемых. Полученные результаты свидетельствуют о необходимости разработки подобных занятий в рамках любой специализации и направленности, так как интегрированные курсы существенно расширяют не только познавательные, но и языковые навыки обучающихся.

Ключевые слова: интеграция; интегративные взаимодействия; межпредметные связи; занятие по иностранному языку; произведение художественной литературы; коммуникативная компетенция; курсант; юридический вуз; уровень знаний; культурологический контекст; профессиональная подготовка; коммуникация; лексические единицы.
} 
На сегодняшний день проблема повышения качества образования в высших учебных заведениях остается наиболее актуальной. Поиск новых методов и подходов к реализации образовательного процесса требует более многогранной подготовки будущих специалистов, обладающих целостным восприятием окружающего мира и себя в нем.

Проблема интегративных взаимодействий, идея анализа литературного произведения в культурологическом контексте имеет свою историю. О межпредметных связях в курсе литературы много и успешно писали ученые-методисты, например, Т.Г. Браже [1], Г.И. Беленький [2], С.А. Леонов [3], Э.Т. Ардаширова [4], Л.В. Шамрей [5], Л.Н. Савина [6], 3.С. Смелкова [7], Т.А. Калганова [8], Л.А. Шевченко [9], Р.Н. Горячева [10] и др. Педагоги-практики в своих публикациях делятся опытом проведения интегрированных занятий по различным предметам (литература и изобразительное искусство, литература и иностранный язык, математика и гуманитарные предметы и т.д.) и обсуждают проблемы интеграции и воспитания и развития обучающихся в контексте диалога культур. В меньшей степени исследованы связи и интегративные взаимодействия по проблеме «литература и иностранный язык». Только в последнее время появились некоторые работы, посвященные использованию на занятиях по иностранному языку межпредметных связей. Данной проблемой методисты занимаются преимущественно в связи с обучением языку студентов факультета иностранных языков и школьников (Е.Н. Калуцкая [11], В.Я. Коровина [12], Л.П. Загородная [13], И.Н. Зотеева, Т.А. Зайцева [14], М.Г. Габайдуллина [15]). И совсем немного работ посвящено особенностям проведения интегрированных занятий в неязыковом вузе (Е.Д. Матрон [16], К.Х. Гадоев [17], С.Н. Казначеева, Р.В. Репина [18]). Поэтому требуется переосмысление теории и практики интегрированного взаимодействия на занятиях иностранного языка в гуманитарных вузах. Так как в результате освоения программы специалитета у выпускника должны быть сформированы общекультурные, общепрофессиональные, профессиональные и профессионально-специализированные компетенции, современная педагогика призывает к синтетическому подходу к образованию. Таким образом, целью нашего исследования является формирование коммуникативной компетенции курсантов юридического ведомственного вуза посредством разработки научно-методических основ интегрированных занятий по иностранному языку и литературе.

Требования современного общества диктуют острую необходимость владения минимум одним иностранным языком специалистами любого профиля подготовки. Компетентность юристов наряду со специальными знаниями во многом определяется умением пользоваться иностранным языком в конкретной научно-исследовательской и практической деятельности, а также в целях установления контактов и международного общения. Дисциплина «Иностранный (английский) язык» входит в базовую часть гуманитарного, социального и экономического цикла дисциплин по специальности «Юриспруденция» и позволяет совершенствовать навыки устной диалогической и монологической речи, развитие ос- новных навыков публичной речи, развитие навыков ознакомительного, поискового, изучающего и просмотрового чтения. Программа данной дисциплины реализуется на фоне общекоммуникативной направленности обучения и междисциплинарного подхода. Иностранный язык - это рабочий инструмент, позволяющий специалисту постоянно совершенствовать свои знания, изучая современную иностранную литературу по соответствующей специальности. Наличие сформированной коммуникативной компетенции дает возможность вести плодотворную деятельность по изучению и творческому осмыслению зарубежного опыта в профилирующих и смежных областях науки, а также в сфере делового профессионального общения [19].

Целями освоения дисциплины «Иностранный (английский) язык» являются повышение уровня владения иностранным языком, достигнутого на предшествующей ступени образования, и овладение курсантами необходимым и достаточным уровнем коммуникативной компетенции для осуществления профессиональной коммуникации в сфере УИС при общении с зарубежными партнерами, а также решения социально-коммуникативных задач в различных областях общекультурной и научной деятельности. Основными задачами данной дисциплины является формирование у обучаемых практических навыков и умений по главным видам речевой деятельности: письмо, чтение, говорение, аудирование. Компонующие материалы данной дисциплины направлены на следующие аспекты:

1. Формирование и совершенствование слухопроизносительных навыков применительно к новому языковому и речевому материалу;

2. Формирование навыков и умений устного монологического и диалогического общения на основе языковых клише, стандартов речи, относящихся к общей, культурологической и страноведческой тематике;

3. Формирование навыков работы с литературой в целях получения необходимой профессиональной или научной информации;

4. Формирование навыков и умений, необходимых для осуществления устной и письменной коммуникации в профессиональной деятельности сотрудника пенитенциарной системы;

5. Формирование навыков реферирования, аннотирования и перевода научной литературы по специальности;

6. Формирование навыков письма, необходимых для ведения деловой переписки и подготовки публикаций;

7. Формирование навыков и умений, необходимых для ведения профессиональной документации на иностранном языке [20].

Так как формирование основных коммуникативных компетенций в рамках курса иностранного языка происходит на основе изучения бытовых текстов и текстов юридической направленности, нашей задачей было расширение программы путем введения в курс литературных произведений англоязычных авторов. Анкетирование, проведенное в начале обучения, отразило низкий уровень знаний обучающихся художественной литературы на иностранном языке, что свидетельствует о целесообразности и правомерности выбранного направления. 
Таким образом, мы пришли к следующим выводам:

- необходимо уделить серьезное внимание повышению эффективности мотивационной деятельности обучающихся; кроме знаний, навыков и умений в овладении английским языком, им необходимо привить чувство ответственности и заинтересованности в овладении не только языком, но и литературой, культурой страны;

- необходимо совершенствовать методическую подготовку преподавателя для грамотной организации учебной деятельности, активизировать самостоятельную работу обучающихся;

- необходимо повысить эффективность интегративных взаимодействий в преподавании иностранного языка и литературы.

Поскольку целью исследования было расширить круг интересов обучающихся, повысить их познавательную мотивацию, а также оценить, насколько изучение литературных произведений на занятиях по иностранному языку углубляет знания курсантов, был разработан курс интегрированных занятий по английскому языку и литературе на основе тематического плана дисциплины.

Задачами включения образцов англоязычной литературы на занятиях иностранного языка являются:

1. Формирование культурного мировоззрения обучающихся, расширение их кругозора посредством знакомства курсантов с различными жанрами и направлениями в художественной литературе, познание национальных традиций страны изучаемого языка через литературное пространство;

2. Формирование самостоятельного эстетического восприятия окружающего мира через осознание замысла работы;

3. Развитие умений работать с художественным произведением, его образами, деталями и персонажами;

Таблица 1 - Курс интегрированных занятий по английскому языку и литературе в юридическом ведомственном вузе

\begin{tabular}{|l|l|}
\hline \multicolumn{1}{|c|}{ Наименование разделов и тем } & \multicolumn{1}{|c|}{ Образцы англоязычной литературы } \\
\hline Вводный курс. Моя биография & $\begin{array}{l}\text { Р. Киплинг стихотворение «Заповедь», } \\
\text { О. Генри «Дары Волхвов» }\end{array}$ \\
\hline $\begin{array}{l}\text { Я - первокурсник } \\
\text { Самарского юридического института }\end{array}$ & М. Твен «Приключения Тома Сойера» \\
\hline $\begin{array}{l}\text { Национальные традиции } \\
\text { и обычаи стран изучаемого языка }\end{array}$ & $\begin{array}{l}\text { Ч. Диккенс «Посмертные записки Пиквикского клуба», } \\
\text { Р. Бернс стихотворение «Красная роза» }\end{array}$ \\
\hline Виды преступлений & Э. По «Похищенное письмо» \\
\hline $\begin{array}{l}\text { Правоохранительные организации мира: } \\
\text { Скотленд-Ярд }\end{array}$ & Р. Стаут «Звонок в дверь» \\
\hline Правоохранительные организации мира: ФБР & К. Дойл «Записки Шерлока Холмса» \\
\hline Правоохранительные организации мира: Интерпол & А. Кристи «Дело об исчезнувшем муже» \\
\hline Виды права & С. Моэм «Человек со шрамом» \\
\hline Судопроизводство зарубежных стран & Ф.С. Фицджеральд «Изверг» \\
\hline Моя будущая профессиональная деятельность & Д. Голсуорси «Присяжный» \\
\hline
\end{tabular}

Интегрированные занятия проводились в рамках каждой изучаемой темы по дисциплине. Необходимо отметить, что в начале обучения курсанты не были заинтересованы в подобном виде работы, однако в процессе деятельности мотивация обучаемых меня-
4. Развитие практических языковых навыков: навыков перевода, произношения, чтения; развитие речи на основе изученной композиции.

Включение литературных произведений в занятия по английскому языку происходило постепенно и поэтапно. Начало обучения предполагает повторение и закрепление основных грамматических и лексических конструкций, и, поскольку обучаемые имеют невысокий уровень владения языком и не полностью готовы к работе с образцами иноязычной литературы, изучение художественных произведений начинается с более простых и адаптированных текстов. В дальнейшем обучение усложнялось за счет введения более сложных композиций и неадаптированных произведений зарубежной литературы и постепенного увеличения часов интегрированных занятий.

При выборе художественных произведений для интегрированных занятиях по иностранному языку и литературе учитывалась также направленность подготовки курсантов, большее предпочтение отдавалось творениям англоязычных писателей, тематика которых соответствовала профессиональной специализации учреждения. Таким образом, на основании лексических единиц, встречающихся в работах авторов, создавался тезаурус обучаемых, необходимый им как на занятиях английского языка, так и в различных речевых ситуациях на профессиональную тему. Конечно же, не все тексты, представленные в рамках серии интегрированных занятий по иностранному языку, включают в себя профессиональную направленность и юридические лексические единицы, так как их отработка не были единственными целями данного курса. Художественные произведения и поэтические творения англоязычных авторов также призваны повысить интерес обучающихся как к литературе и культуре страны изучаемого языка, так и к иностранному языку в целом (табл. 1). лась, появлялась заинтересованность, менялось отношение к занятиям иностранного языка, появлялась потребность в чтении.

При изучении художественных произведений в рамках интегрированного курса иностранного языка 
и литературы также усложнялись методы работы с текстом. Если на первых этапах основной акцент делался на отработке фонетических навыков, умениях извлечения полной и фрагментарной информации из произведения, говорении в монологической форме на базе прочитанного, то на более продвинутом уровне больше внимания уделялось развитию коммуникативных умений на основе изученного материала.

Обсуждение прочитанного на иностранном языке является важным коммуникативным умением и позволяет значительно обогатить устно-речевую коммуникацию обучающихся, сделать ее более содержательной и мотивированной. В отличие от школьника, которому свойственно стремление к элементарной характеристике героя, учащийся высшего учебного заведения способен к более широким образным обобщениям характеров, взаимоотношений между людьми. В юношеском возрасте наблюдается стремление к развернутой, аргументированной характеристике, которая, как правило, складывается в результате сопоставления и сравнения поведения людей на разных отрезках жизненного пути и в разных ситуациях.

В процессе проведения интегрированных занятий необходимо было рассмотреть, как литературные произведения воспринимаются обучаемыми и как их изучение влияет на уровень усвоения программы иностранного языка.

Были определены уровни усвоения обучающимися литературного и языкового пространства, охватывающие знание о культуре, литературе стран изучаемого языка, а также следующие речевые навыки:

- высокий уровень - основательные, системные знания по страноведению, литературе, культуре стран изучаемого языка; личностная заинтересованность в получении знаний; активное участие в литературно-языковой деятельности; сформированность коммуникативных навыков;

- средний уровень - общие, несистемные знания по страноведению, литературе, культуре стран изучаемого языка; культурологические потребности выражены не всегда; частичное участие в литературноязыковой деятельности; частичная сформированность коммуникативных навыков;

- низкий уровень - фрагментарные знания по страноведению, литературе, культуре стран изучаемого языка; культурологические потребности не возникают; низкое участие в литературно-языковой деятельности; слабая сформированность коммуникативных навыков.

Результаты контрольного среза знаний на выявление уровней культурологического и языкового развития курсантов показали, что обучающиеся по программе интегрированных занятий иностранного языка и литературы имеют не только более высокие уровни историко-литературного развития, но и более высокие показатели сформированности коммуникативных навыков английского языка. Средний балл в экспериментальной группе представляется выше, чем в контрольной группе (табл. 2).

Анализ результатов подтверждает целесообразность разработки интегрированного курса по иностранному языку и литературе, так как анализ художественных произведений на занятиях английского языка положительно влияет как на речевое, так и на социокультурное развитие обучающихся. таблица 2 - Степень влияния литературных знаний на уровень языковой компетенции курсантов

\begin{tabular}{|c|c|c|c|}
\hline \multicolumn{2}{|c|}{$\begin{array}{c}\text { Контрольная } \\
\text { группа }\end{array}$} & \multicolumn{2}{|c|}{$\begin{array}{c}\text { Экспериментальная } \\
\text { группа }\end{array}$} \\
\hline Констати- & Контроль- & Констати- & Контроль- \\
\hline $\begin{array}{l}\text { экспери- } \\
\text { мент }\end{array}$ & $\begin{array}{l}\text { экспери- } \\
\text { мент }\end{array}$ & $\begin{array}{l}\text { экспери- } \\
\text { мент }\end{array}$ & $\begin{array}{l}\text { экспери- } \\
\text { мент }\end{array}$ \\
\hline 3,1 & 3,8 & 3 & 4,1 \\
\hline
\end{tabular}

Таким образом, практика показывает, что обучаемые с интересом относятся к занятиям, на которых происходит интеграция английского языка и литературы. Изучаемый материал обогащает представления и знания курсантов не только собственно предметные, но и о культуре, искусстве, литературе, развивает воображение и креативные способности. Усвоение лексических единиц, необходимых курсантам в их профессиональной деятельности, через литературное пространство не только позволяет закрепить лексический материал с минимальными затратами аудиторного времени и повышает мотивацию к учению, но и повышает результаты обучения иностранному языку.

Изучение культурного пространства, которое моделируется с помощью художественной литературы на занятиях по иностранному языку, практика культуроведческого наполнения занятия подразумевает овладение социокультурными знаниями и умениями, что обеспечивает реализацию воспитательной, общеобразовательной и практической целей обучения иностранному языку.

\section{СПИСОК ЛИТЕРАТУРЫ:}

1. Браже Т.Г. Интеграция предметов в современной школе // Литература в школе. 1996. № 5. С. 150154.

2. Беленький Г.И. Интеграция? Об уроках словесности // Литература в школе. 1998. № 8. С. 86-90.

3. Леонов С.А. Интегрированный урок литературы. М., 1999. 170 с.

4. Ардаширова Э.Т. Интегративно-образовательный конструкт - эстетическая педагогика: методологические проблемы и поиски преобразования педагогической теории // Методологические проблемы развития образования. Уфа, 1997. С. 70-80.

5. Шамрей Л.В. Функциональные закономерности взаимодействия науки и искусства в школьном изучении литературы: автореф. дис. ... д-ра пед. наук. СПб., 1996. 45 с.

6. Савина Л.Н. Интегрированные уроки литературы и методика их проведения в выпускном классе // Проблемы современного филологического образования. Вып. 4 / под ред. С.А. Леонова. М.; Ярославль, 2003. С. $183-196$.

7. Смелкова 3.С. Педагогическое общение: Теория и практика учебного диалога на уроках словесности. М., 1999. 232 с.

8. Калганова Т.А. К проблеме интеграции русского языка и литературы // Русская словесность. 1999. № 5. С. 24-26.

9. Шевченко Л.А. Об интеграции на уроках литературы // Литература в школе. 1996. № 5. С. 154-156.

10. Горячева Р.Н. Алгоритм учебно-речевой деятельности «учитель - ученик» как условие эффек- 
тивности интегрированного урока литературы: автореф. дис. ... канд. пед. наук. Самара, 2000. 20 с.

11. Калуцкая Е.Н. Особенности интегрированного урока литературы в старших классах средней школы (на примере литературы и немецкого языка): дис. ...канд. пед. наук. Самара, 2004. 183 с.

12. Коровина В.Я. Методические основы совершенствования устной речи учащихся в процессе изучения литературы в школе: автореф. дис. ...д-ра пед. наук. М., 1994. 39 с.

13. Загородная Л.П. О разработке интегрированного курса «иностранный язык + художественное развитие» // Иностранные языки в школе. 1992. № 3. C. $3-12$.

14. Зотеева И.Н., Зайцева Т.А. О функциях межпредметных связей при обучении французскому языку в средней школе // Иностранные языки в школе. 1995. № 1. С. 42-45.

15. Габдуллина М.Г. Разработка проблемных заданий в процессе преподавания литературы на английском языке в X-XI кл. // Иностранные языки в школе. 2005. № 4. С. 33-37.
16. Матрон Е.Д. Художественное произведение на уроках иностранного языка: учебное пособие. М., 2002. $296 \mathrm{c}$.

17. Гадоев К.Х. Интегрированное обучение иностранному (английскому) языку в неязыковых вузах республики Таджикистан: дис. ...канд. пед. наук. Душанбе, 2015. 164 с.

18. Казначеева С.Н., Репина Р.В. Интеграция иностранного языка с другими дисциплинами на основе личностно-деятельностного подхода с целью развития познавательной активности студентов [Электронный ресурс] // Интернет-журнал «Мир науки» 2016. T. 4, № 1. - http://mir-nauki.com/pdf/ 16dmn116.pdf.

19. Гиренок Г.А. Формирование коммуникативной компетенции будущих сотрудников УИС в высшей профессиональной школе: автореф. дис. ... канд. пед. наук. Самара, 2013. 25 с.

20. Рабочая программа учебной дисциплины «Иностранный (английский) язык» ФКОУ ВО СЮИ ФСИН России / сост. Г.А. Гиренок, О.О. Скобелева. Самара, 2016. 37 с.

\section{INTEGRATED ENGLISH AND LITERATURE COURSE IN LAW SCHOOLS SPONSORED BY GOVERNMENT AGENCIES}

(C) 2017

Skobeleva Oksana Olegovna, candidate of pedagogical sciences, deputy head of Philosophy and Humanities Department

Samara Law Institute of the Federal Penitentiary Service of Russia (Samara, Russian Federation)

Abstract. This paper deals with the problem of improving linguistic and cultural skills of students by introducing integrated foreign language and literature classes into the educational process. The integration of cultures in the departmental law institutions is an important element in the training of specialists whose competence is largely determined by their professional skills as well as by the ability to use a foreign language in terms of establishing contacts with representatives of other cultures and the ability to work independently with scientific and practical documentation and literature, to conduct business correspondence and negotiations. The work outlines the basis for the development of an integrative course of English and literature and offers a series of sessions on interdisciplinary interactions. The conducted researches have shown that interdisciplinary connections in foreign language classes have a positive impact on the quality of the educational process: cadet's horizons are expanding, motivational aspect of training is increasing, educational and research activity is becoming more active, moral education is formed, and communicative skills of trainees are developing. The obtained results testify to the need to develop such classes within any specialization and orientation, since integrated courses significantly expand cognitive and language skills of students.

Keywords: integration; integrative interactions; interdisciplinary integration; foreign language studies; fiction book; communicative competence; cadet; law school; level of knowledge; cultural context; vocational training; communication; lexical units.

УДК 378.147

Статья поступила в редакцию 03.05.2017

\section{ОСОБЕННОСТИ ИЗУЧЕНИЯ КУРСА «НЕКЛАССИЧЕСКИЕ ЗАДАЧИ МАТЕМАТИЧЕСКОЙ ФИЗИКИ» В УСЛОВИЯХ РЕАЛИЗАЦИИ КОМПЕТЕНТНОСТНОГО ПОДХОДА К ПОДГОТОВКЕ МАГИСТРОВ ПЕДАГОГИЧЕСКОГО ОБРАЗОВАНИЯ}

(C) 2017

Холодовский Святослав Евгеньевич, доктор физико-математических наук, профессор кафедры фундаментальной и прикладной математики, теории и методики обучения математике Кононенко Наталья Васильевна, кандидат педагогических наук, доцент кафедры фундаментальной и прикладной математики, теории и методики обучения математике Токарева Юлия Сергеевна, кандидат физико-математических наук, декан факультета естественных наук, математики и технологий Забайкальский государственный университет (2. Чита, Российская Федераиия)

Аннотация. В статье рассматриваются теоретические, методологические и методические аспекты реализации компетентностного подхода к подготовке магистров педагогического образования физико-математи- 